Available online at website :

http://uinjkt.ac.id /index.php/elementar

Elementar (Elementary of Tarbiyah): Jurnal Pendidikan Dasar, 1(2), 2021, 193-201

\title{
Systematic Literature Review: Hasil Kerajinan Tangan Dalam Kajian Etnomatematika
}

\author{
Sisfarina Hafifah ${ }^{1)}$, Aan Putra ${ }^{2)}$ \\ Tadris Matematika, FTIK, Institut Agama Islam Negari Kerinci \\ Jl. Pelita IV, Semur Gedang, Pesisir Bukit, Kabupaten Kerinci, Jambi 37112 \\ E-mail:sisfa2002@gmail.com, aanputra283@gmail.com
}

\section{Corresponding Author:}

Sisfarina Hafifah

Submit: 12 September 2021

Revisi: 12 Oktober 2021

Approve: 30 Desember 2021

Pengutipan: Sisfarina

Hafifah, dkk. (2022).

Systematic Literature Review:

Hasil Kerajinan Tangan

Dalam Kajian

Etnomatematika. Elementar

(Elementary of Tarbiyah): Jurnal

Pendidikan Dasar, 1(2), 2020,

193-201. elementar.v1i2

24203.

\section{Abstract}

This article discusses about improving mathematics learning in ethnomathematical learning through handicrafts. This study aims to conduct an ethnomathematical study of the results of handicrafts and their relation to mathematics learning. The research method chosen in this study is the SLR (Systematic Literature Review) method. Data collection is done by documenting and reviewing all articles regarding the results of handicrafts. The articles used in this study were 14 accredited national journal articles obtained from the Google Scholar database. Based on this research, it was found that the results of handicrafts in ethnomathematical studies can improve mathematics learning.

Keywords: Handicraft Results, Ethnomathematics, Systematic Literature Review

\begin{abstract}
Abstrak
Artikel ini membahas tentang meningkatkan pembelajaran matematika pada pembelajaran etnomatematika melalui hasil kerajinan tangan. Penelitian ini bertujuan untuk melakukan kajian etnomatematika tentang hasil kerajinan tangan dan kaitannya dengan pembelajaran matematika. Metode penelitian yang dipilih dalam penelitian ini ialah metode SLR (Systematic Literature Review). Pengumpulan data dilakukan dengan mendokumentasi dan mereviu semua artikel mengenai hasil kerajian tangan. Artikel yang digunakan pada penelitian ini sebanyak 14 artikel jurnal nasional terakreditasi yang diperoleh dari database Google Scholar. Berdasarkan penelitian ini didapatkan bahwa hasil kerajinan tangan dalam kajian etnomatematika dapat meningkatkan pembelajaran matematika.
\end{abstract}

Keywords: Hasil Kerajinan Tangan, Etnomatematika, Systematic Literature Review 


\section{PENDAHULUAN}

Negara Indonesia dikenal sebagai negara dengan beraneka ragam budaya maupun tradisi mulai dari Sabang hingga Merauke kebudayaan yang dimiliki sangatlah mempesona (Puspitasari et al., 2020). Pendidikan dan budaya adalah sesuatu yang tidak dapat dihindari dalam kehidupan seharihari, karena budaya merupakan kesatuan utuh dan menyeluruh yang berlaku dalam masyarakat (Kusumawati et al., 2018).

Integrasi etnomatematika dan menyimpulkan bahwa peran etnomatematika sangatlah penting sebagai sarana untuk memotivasi, menstimulasi peserta didik, dapat mengatasi kejenuhan dan memberikan nuansa baru pada pembelajaran matematika (Abi, 2016). Sebagian besar siswa mengalami kesulitan dalam mengaplikasikan matematika dalam kehidupan sehari-harinya karena dalam pembelajaran matematika dunia nyata hanya dijadikan tempat mengaplikasikan konsep bukan sebagai alat dan sumber dalam mempelajari pengetahuan matematika (Dahlan \& ., 2018).

$$
\text { Penerapan pendidikan budaya }
$$

berbasis ethnomathematika yang diintegrasikan ke dalam pembelajaran dapat melalui pengembangan instrumen pembelajaran (Agustin et al., 2019). Etnomatematika sebagai suatu pendidikan matematika yang mengintegrasikan nilai-nilai kultur dalam pembelajaran matematika perlu menggagas integrasi secara nyata nilai-nilai kultur tersebut (Sirate, 2015). Keterampilan matematika yang dipelajari oleh peserta didik di sekolah tidak terkontruksi secara logis dan berdasarkan pada struktur kognitif abstrak, melainkan sebagai kombinasi pengetahuan dan keterampilan yang telah diperoleh sebelumnya serta sebagai masukan (budaya) baru (S. Sirate, 2012).

Etnomatematika adalah bentuk matematika yang dipengaruhi atau didasarkan budaya. Salah satu pendekatan yang dapat memberikan kesempatan kepada siswa dalam meningkatkan kemampuan komunikasi matematis adalah pembelajara kontruktivisme serta pembelajaran berbasis budaya (Agustin et al., 2019). Etnomatematika merupakan salah satu bentuk strategi pembelajaran matematika yang mengaitkan kearifan budaya lokal dalam pembelajaran matematika (Wahyuni \& Pertiwi, 2017). Tujuan dari adanya etnomatematika adalah untuk mengakui bahwa ada cara-cara berbeda dalam melakukan matematika dengan mempertimbangkan pengetahuan matematika akademik yang dikembangkan oleh berbagai sektor masyarakat serta dengan mempertimbangkan modus yang berbeda di mana budaya yang berbeda merundingkan praktek matematika mereka (cara mengelompokkan, berhitung, mengukur, merancang bangunan atau alat, bermain dan lainnya) (Wahyuni \& Pertiwi, 2017).

Kerajinan tangan merupakan salah satu kekayaan kebudayaan Indonesia 
(Kusumawati et al., 2018). Kerajinan merupakan salah satu hasil budaya yang sudah ada sejak zaman nenek moyang. Pada awalnya kerajinan timbul dari dorongan manusia itu sendiri dengan membuat alat-alat kebutuhan seharihari. Dengan perkembangan masyarakat selanjutnya produk kerajinan mulai dibutuhkan (Puspitasari et al., 2020).

Penelitian yang dilakukan oleh (Puspitasari et al., 2020) pada hasil kerajianan tangan masyarakat desa Sodo kecamatan Paliyan yaitu Tompo menunjukkan unsur matematika yaitu penggunaan prinsip tesalasi atau pengubinan, motif anyaman yang memiliki bentuk geometri bangun datar berbentuk persegi atau persegi panjang dengan pengubinan satu jenis bangun datar untuk satu.

Penelitian yang dilakukan oleh (Wulandari \& Nuhamara, 2020) pada hasil kerajian tangan tenun ikat Sumba Timur yang dapat diidentifikasi berdasarkan motif yang ditemui yaitu garis, sudut, bangun datar seperti segitiga, jajargenjang, persegi panjang dan belah ketupat, serta transformasi geometri diantaranya ada rotasi, refleksi, dilatasi dan translasi. Berdasarkan beberapa penelitian diatas peneliti tertarik untuk melakukan studi literatur terhadap etnomatematika pada hasil kerajinan tangan, sehingga peneliti dapat menerapkannya dalam pembelajaran matematika.

\section{METODE}

Systematic Literature Review (SLR) dilakukan dengan mengidentifikasi, mengkaji, mengevaluasi, serta menafsirkan semua penelitian yang tersedia. Penelitian ini dilakukan mereviu dan mengidentifikasi jurnal - jurnal secara terstruktur yang setiap prosesnya mengikuti langkah - langkah yang telah ditetapkan (Triandini, Jayanatha, Indrawan, Putra, \& Iswara, 2019).

Pertanyaannya adalah bagaimana pengaruh positif hasil kerajianan tangan sebagai sumber pembelajaran? (PP1), bagaimana kekurangan hasil kerajianan tangan sebagai sumber pembelajaran? (PP2). Penelitian ini menampunkan artikel jurnal pada database Google Schoolar. Dengan kata kunci adalah Hasil Kerajinan Tangan, Etnomatematika, dan Pembelajaran Matematika. Dari berbagai artikel, peneliti memilih 14 artikel yang terkait erat dengan kata kunci yang digunakan.

Langkah selanjutnya, peneliti mengelompokkan artikel - artikel yang ada hasil kerajinan tangan baik berhubungan dengan pembelajaran matematika maupun hasil belajar secara umum. Meta data artikel artikel tersebut ditabulasi dalam tabel yang meliputi nama penulis, tahun terbit, judul, dan hasil penelitian. Setelah itu, peneliti mereviu dan menganalisis artikel tersebut secara mendalam terutama mengenai hasil penelitian. 
HASIL DAN PEMBAHASAN

Hasil data penelitian yang dimasukkan dalam kajian literatur ini adalah analisis dan rangkuman dari artikel yang didokumentasi terkait, yang disajikan pada Tabel 1 berikut:

Tabel 1. Deskripsi Penelitian Terkait Hasil Kerajian Tangan

\begin{tabular}{|c|c|c|}
\hline Peneliti & Judul Penelitian & Hasil Penelitian \\
\hline (Isnaini, 2019) & $\begin{array}{c}\text { Kerajinan Tenunan } \\
\text { Anyaman Bali Terdapat } \\
\text { Unsur Etnomatematika }\end{array}$ & $\begin{array}{l}\text { Sebagai sumber belajar dan bisa } \\
\text { membuat pelajar lebih memahami } \\
\text { bagaimana budaya mereka } \\
\text { berhubungan dengan matematika. }\end{array}$ \\
\hline (Dominikus, 2019) & $\begin{array}{l}\text { Etnomatematika Dalam } \\
\text { Kerajinan Tangan } \\
\text { Anyaman Masyarakat Desa } \\
\text { Waktkamba } \\
\text { Kecamatan Maurole } \\
\text { Kabupaten Ende }\end{array}$ & $\begin{array}{l}\text { Adanya penggunaan prinsip } \\
\text { pengubinan yang merupakan suatu pola } \\
\text { khusus yang terdiri dari bangun - } \\
\text { bangun geometri yang disusun tanpa } \\
\text { jarak untuk menutupi suatu bidang } \\
\text { datar dan adanya prinsip perkalian dan } \\
\text { barisan aritmatika pada proses } \\
\text { pembuatan anyaman. }\end{array}$ \\
\hline (Suciati \& Kusuma, 2019) & $\begin{array}{c}\text { Eksplorasi } \\
\text { Etnomatematika Pada } \\
\text { Anyaman Bambu }\end{array}$ & $\begin{array}{l}\text { Dari empat daerah terdapat perbedaan } \\
\text { ciri khas dalam pembuatan anyaman } \\
\text { dua dimensi dan tiga dimensi. }\end{array}$ \\
\hline (Puspitasari et al., 2020) & $\begin{array}{l}\text { Etnomatematika Kerajinan } \\
\text { Tangan Anyaman Bambu } \\
\text { Masyarakat Desa Sodo } \\
\text { Kecamatan Paliyan Sebagai } \\
\text { Bahan Pembelajaran } \\
\text { Matematika }\end{array}$ & $\begin{array}{l}\text { Penggunaan prinsip tesalasi atau } \\
\text { pengubinan, motif anyaman yang } \\
\text { memiliki bentuk geometri bangun datar } \\
\text { berbentuk persegi atau persegi panjang } \\
\text { dengan pengubinan satu jenis bangun } \\
\text { datar untuk satu kerajinan. }\end{array}$ \\
\hline $\begin{array}{c}\text { (Prabawati \& Muslim, } \\
\text { 2020) }\end{array}$ & $\begin{array}{c}\text { Eksplorasi } \\
\text { Etnomatematika Dari Para } \\
\text { Pengrajin Payung Geulis } \\
\text { Tasikmalaya Jawa Barat }\end{array}$ & $\begin{array}{l}\text { Terdapat kaitan antara Payung Geulis } \\
\text { dengan matematika yang ditunjukkan } \\
\text { dengan adanya unsur-unsur } \\
\text { matematika berdasarkan konsep } \\
\text { geometri. }\end{array}$ \\
\hline (Bito et al., 2021) & $\begin{array}{c}\text { Konten Matematika } \\
\text { Sekolah Dasar pada } \\
\text { Rumah Adat Lio di } \\
\text { Kampung Waka Ende } \\
\text { NTT }\end{array}$ & $\begin{array}{l}\text { Rumah adat Waka mengandung unsur } \\
\text { matematika sekolah dasar. Konsep } \\
\text { matematika yang ditemukan pada } \\
\text { rumah adat di Kampung Waga } \\
\text { didominasi oleh konsep unsur-unsur } \\
\text { geometri primitive. }\end{array}$ \\
\hline $\begin{array}{l}\text { (Wulandari \& Nuhamara, } \\
2020 \text { ) }\end{array}$ & $\begin{array}{l}\text { Eksplorasi Tenun Ikat } \\
\text { Sumba Timur Ditinjau } \\
\text { Dari Etnomatematika }\end{array}$ & $\begin{array}{l}\text { Ditemukan beberapa motif yang sering } \\
\text { ditenun, dan beberapa unsur matematis } \\
\text { dalam tenun ikat Sumba Timur yang } \\
\text { berdasarkan motif yang ditemui yaitu } \\
\text { garis, sudut, bangun datar }\end{array}$ \\
\hline (Fajar et al., 2018) & $\begin{array}{c}\text { Etnomatematika } \\
\text { Pembuatan Kerajinan } \\
\text { Tangan Anyaman Bambu } \\
\text { Masyarakat Osing Di Desa } \\
\text { Gintangan Banyuwangi } \\
\text { Sebagai Bahan Ajar } \\
\text { Geometri }\end{array}$ & $\begin{array}{l}\text { Diperoleh etnomatematika yang } \\
\text { meliputi aktivitas menghitung, } \\
\text { mengukur, dan mendesain. }\end{array}$ \\
\hline $\begin{array}{c}\text { (Puspadewi \& Putra, } \\
\text { 2014) }\end{array}$ & $\begin{array}{l}\text { Etnomatematika di Balik } \\
\text { Kerajinan Anyaman Bali }\end{array}$ & $\begin{array}{l}\text { Hasil-hasil kerajinan anyaman } \\
\text { dimanfaatkan dalam pembelajaran di } \\
\text { kelas terutama sebagai sumber belajar. }\end{array}$ \\
\hline
\end{tabular}




\begin{tabular}{|c|c|c|}
\hline (Ayu et al., 2020) & $\begin{array}{l}\text { Study Etnomatematika } \\
\text { Pada Aktivitas Pengrajin } \\
\text { Anyaman Bambu } \\
\text { Masyarakat Sejangkung }\end{array}$ & $\begin{array}{l}\text { Terdapat muatan matematika pada } \\
\text { aktivitas pengrajin anyaman bambu } \\
\text { masyarakat Sejangkung. }\end{array}$ \\
\hline (Sayu, 2013) & $\begin{array}{l}\text { Eksplorasi } \\
\text { Etnomatematika Dalam } \\
\text { Menganyam Caping } \\
\text { Masyarakat Dayak Ribun }\end{array}$ & $\begin{array}{l}\text { Dalam pewarnaan dari komunitas } \\
\text { Dayak terdapat menghitung, } \\
\text { mengukur, mendesain, menemukan, } \\
\text { dan menghapus. }\end{array}$ \\
\hline (Purnama et al., 2020) & $\begin{array}{c}\text { Eksplorasi } \\
\text { Etnomatematika dalam } \\
\text { Motif Tenun Kain Lunggi } \\
\text { Sambas Kalimantan Barat } \\
\text { dan Implikasinya terhadap } \\
\text { Pembelajaran Matematika }\end{array}$ & $\begin{array}{l}\text { Terdapat proses pembuatan motif } \\
\text { tenun kain Lunggi transformasi, motif } \\
\text { tenun kain Lunggi geometri dimensi } \\
\text { satu dan motif tenun kain Lunggi } \\
\text { geometri dimensi dua. }\end{array}$ \\
\hline $\begin{array}{c}\text { (Ratuanik \& Kundre, } \\
\text { 2018) }\end{array}$ & $\begin{array}{c}\text { Pemanfaatan } \\
\text { Etnomatematika } \\
\text { Kerajinan Tangan } \\
\text { Anyaman Masyarakat } \\
\text { Maluku Tenggara Barat } \\
\text { Dalam Pembelajaran }\end{array}$ & $\begin{array}{l}\text { Kerajinan tangan anyaman yang } \\
\text { mengandung unsur matematika, jadi } \\
\text { dapat dimanfaatkan dalam } \\
\text { pembelajaran di kelas sebagai sumber } \\
\text { belajar. }\end{array}$ \\
\hline (Fauzi et al., 2020) & $\begin{array}{l}\text { Eksplorasi Budaya Sasak } \\
\text { Sebagai Sumber Belajar } \\
\text { Matematika Sekolah Dasar }\end{array}$ & $\begin{array}{l}\text { Sebagai sumber pembelajaran } \\
\text { matematika, terutama pada unsur - } \\
\text { unsur geometri persegi panjang, } \\
\text { segitiga, kerucut, piramida. }\end{array}$ \\
\hline
\end{tabular}

Dari hasil penelusuran diperoleh 14 artikel yang memenuhi kriteria inklusi setelahmembaca judul, abstrak, serta isi dari kesimpulan literature. Secara keseluruhan, literature yang diterbitkan pada tahun 2013 sebanyak 1 artikel, 2014 sebanyak 1 artikel, 2018 sebanyak 2 artikel, 2019 sebanyak 3 artikel, 2020 sebanyak 6 artikel, 2021 sebanyak 1 artikel.

1. Pengaruh Positif Hasil Kerajinan Tangan Sebagai Sumber Pembelajaran
Berdasarkan 14 artikel yang diseleksi, semua artikel menunjukkan hasil kerajinan tangan berpengaruh positif terhadap siswa. Kajian dampak positif dan dampak negatif dianalisis dengan metode analisis isi (content analysis). Hasil analisis pengaruh positif hasil kerajinan tangan sebagai sumber belajar disajikan pada tabel 2 berikut:

Tabel 2. Pengaruh Positif Hasil Kerajinan Tangan Sebagai Sumber Pembelajaran

\begin{tabular}{|c|c|}
\hline Peneliti dan Tahun & $\begin{array}{c}\text { Pengaruh Positif Hasil Kerajinan Tangan dalam } \\
\text { Pembelajaran }\end{array}$ \\
\hline (Isnaini, 2019) & $\begin{array}{l}\text { Sebagai sumber belajar dan bisa membuat pelajar lebih } \\
\text { memahami }\end{array}$ \\
\hline (Dominikus, 2019) & $\begin{array}{l}\text { Mengetahui sejarah awal adanya kerajinan tangan } \\
\text { anyaman }\end{array}$ \\
\hline (Suciati \& Kusuma, 2019) & Dapat mengetahui unsur matematika \\
\hline (Puspitasari et al., 2020) & $\begin{array}{l}\text { Menambah wawasan siswa, Meningkatkan motivasi } \\
\text { dalam belajar }\end{array}$ \\
\hline
\end{tabular}




\begin{tabular}{ll}
\hline Prabawati \& Muslim, 2020) & $\begin{array}{l}\text { Dapat dijadikan sumber bagi mata pelajaran } \\
\text { matematika } \\
\text { (Bito et al., 2021) }\end{array}$ \\
Mampu memperkaya pengetahuan \\
(Wulandari \& Nuhamara, 2020) & Meningkatkan motivasi dalam belajar \\
(Fajar et al., 2018) & $\begin{array}{l}\text { Terdapat etomatematika pada aktivitas membuat } \\
\text { kerajinan tangan anyaman }\end{array}$ \\
(Puspadewi \& Putra, 2014) & $\begin{array}{l}\text { Sebagai sumber belajar dalam pembelajaran, } \\
\text { meningkatkan motivasi dalam belajar }\end{array}$ \\
(Ayu et al., 2020) & $\begin{array}{l}\text { Terdapat muatan matematika } \\
\text { (Sayu, 2013) }\end{array}$ \\
(Purnama et al., 2020) & Sebagai sumber belajar matematika \\
(Ratuanik \& Kundre, 2018) & Sumber bahan belajar matematika \\
(Fauzi et al., 2020) & Sebagai sumber belajar
\end{tabular}

Beberapa penelitian mengungkapkan bahwa hasil kerajinan tangan sebagai sumber pembelajaran meningkatkan motivasi dalam belajar (Wulandari \& Nuhamara, 2020; Puspadewi \& Putra, 2014), Sebagai sumber belajar matematika (Sayu, 2013; Isnaini, 2019; Ratuanik \& Kundre, 2018; Puspadewi \& Putra, 2014; Muslim, \& Prabawati, 2019), sebagai sumber belajar matematika (Fauzi et al., 2020), sebagai sumber bahan belajar matematika (Purnama et al., 2020), terdapat muatan matematika (Ayu et al., 2020), menambah wawasan siswa (Puspitasari et al.,
2020), dapat mengetahui unsur matematika (Suciati \& Kusuma, 2019), mampu memperkaya pengetahuan (Bito et al., 2021).

2. Kekurangan Hasil Kerajinan Tangan Sebagai Sumber Belajar

Berdasarkan 14 artikel yang diseleksi, tidak ditemuakan satupun artikel yang menunjukakan kekurangan hasil kerajinan tangan dari hasil analisis isi (content analysis). Tabel hasil analis dampak negatif hasil kerajinan tangan sebagai sumber pembelajaran disajikan dalam tabel 3 berikut:

Tabel 3. Dampak Negatif Hasil Kerajinan Tangan Sebagai Sumber Pembelajaran

\begin{tabular}{lc}
\hline \multicolumn{1}{c}{ Peneliti dan Tahun } & $\begin{array}{c}\text { Pengaruh Negatif Hasil Kerajinan Tangan dalam } \\
\text { Pembelajaran }\end{array}$ \\
\hline (Isnaini, 2019) & Tidak dijelaskan \\
(Dominikus, 2019) & Tidak dijelaskan \\
(Suciati \& Kusuma, 2019) & Tidak dijelaskan \\
\hline (Puspitasari et al., 2020) & Tidak dijelaskan
\end{tabular}


(Prabawati \& Muslim, 2020)

(Bito et al., 2021)

(Wulandari \& Nuhamara, 2020)

(Fajar et al., 2018)

(Puspadewi \& Putra, 2014)

(Ayu et al., 2020)

(Sayu, 2013)

(Purnama et al., 2020)

(Ratuanik \& Kundre, 2018)

(Fauzi et al., 2020)
Tidak dijelaskan

Tidak dijelaskan

Tidak dijelaskan

Tidak dijelaskan

Tidak dijelaskan

Tidak dijelaskan

Tidak dijelaskan

Tidak dijelaskan

Tidak dijelaskan

Tidak dijelaskan
Tidak ditemukan satupun artikel yang menyatakan kekurangan hasil kerajinan tangan sebagai sumber pembelajaran. Berarti hasil kerajinan tangan pada pembelajaran tidak bisa digunakan dalam meningkatkan motivasi belajar, sumber belajar matematika, bahan belajar, dan wawasan siswa mengenai keberadaan matematika yang ada pada unsur budaya yang mereka miliki.

\section{KESIMPULAN}

Dapat disimpulkan bahwa hasil kerajinan tangan pada pembelajaran berpengaruh positif dalam meningkatkan motivasi belajar, sumber belajar matematika, bahan belajar, dan wawasan siswa mengenai keberadaan matematika yang ada pada unsur budaya yang mereka miliki. Kajian literatur hasil kerajinan tangan pada pembelajaran ini diharapkan dapat dijadikan pijakan bagi pengembangan hasil kerajinan tangan pada pembelajaran matematika.

\section{DAFTAR PUSTAKA}

Abi, A. M. (2016). Integrasi Etnomatematika Dalam Kurikulum Matematika Sekolah. JPMI Jurnal Pendidikan Matematika Indonesia), $\quad 1(1), \quad 1$. https://doi.org/10.26737/jpmi.v1i1.7 5

Agustin, R. D., Ambarawati, M., \& Era Dewi Kartika, E. D. (2019). Ethnomatematika: Budaya dalam Pembelajaran Matematika. Laplace: Jurnal Pendidikan Matematika, 2(1), 11-18. https://doi.org/10.31537/laplace.v2i 1.190

Ayu, G., Hartoyo, A., \& Nursangaji, A. (2020). Study Etnomatematika Pada Aktivitas Pengrajin Anyaman Bambu Masyarakat 
Sejangkung. Jurnal Pendidikan Dan Pembelajaran Khatulistiwa, 9(9), 1-8.

Bito, G. S., Limana, H. D., \& Dole, F. B. (2021). Ethnomathematics: Primary School Mathematics Contents on Lio Traditional House at Waka Village in Ende NTT. Musamus Journal of Primary Education, 3(2), 125-133. https://doi.org/10.35724/musjpe.v3i 2.3377

Dahlan, J. A., \& . N. (2018). Integrasi Budaya Masyarakat Dalam Pembelajaran Matematika: Contoh Dalam Pembelajaran Sistem Persamaan Linear Dua Variabel. Jurnal Penelitian Dan Karya Ilmiah, 18(1), 15-31.

https://doi.org/10.33592/pelita.v18i 1.25

Dominikus, W. (2019). mengetahui sejarah awal adanya kerajinan tangan anyaman masyarakat desa Watukamba kecamatan Maurole. 5(1), 94-102.

Fajar, F. A., Sunardi, \& Yudianto, E. (2018). Etnomatematika Pembuatan Kerajinan Tangan Anyaman Bambu Masyarakat Osing Di Desa Gintangan Banyuwangi Sebagai Bahan Ajar Geometri. Journal of the Japanese Society of Pediatric Surgeons, $5(2)$, 381. https://doi.org/10.11164/jjsps.5.2_3 81_2

Fauzi, A., Rahmatih, A. N., Sobri, M., Radiusman, R., \& Widodo, A. (2020). Etnomatematika: Eksplorasi Budaya
Sasak sebagai Sumber Belajar Matematika Sekolah Dasar. Jurnal Review Pembelajaran Matematika, 5(1), 1-13. https://doi.org/10.15642/jrpm.2020. 5.1.1-13

Isnaini, L. (2019). Kerajinan Tenunan Anyaman Bali terdapat Unsur Etnomatematika. Jurnal MathEducation Nusantara, 2(1), 28-34.

Kusumawati, R., Banjarnahor, H., \& Dharma, U. S. (2018). Poligon dalam kerajinan papua. Pendidikan Matematika Universitas Muhammadiyah Purworejo, Ruang Seminar UMP, 27-31.

Prabawati, M. N., \& Muslim, S. R. (2020). Eksplorasi Etnomatematika Dari Para Pengrajin Payung Geulis Tasikmalaya Jawa Barat. Prosiding Sesiomadika, 2009, 1270-1285.

https://journal.unsika.ac.id/index.ph $\mathrm{p} /$ sesiomadika/article/view/3112

Purnama, R., Utami, C., \& Prihatiningtyas, N. C. (2020). Eksplorasi Etnomatematika dalam Motif Tenun Kain Lunggi Sambas Kalimantan Barat dan Implikasinya terbadap Pembelajaran Matematika. 3(1), 36-48.

Puspadewi, K. R., \& Putra, I. G. N. N. (2014). Etnomatematika di Balike Kerajinan Anyaman Bali. Jurnal Matematika, 4(2), 80-89.

Puspitasari, N. D., Sekarpandan, M., \& ... (2020). Etnomatematika Kerajinan Tangan Anyaman Bambu Masyarakat 
Desa Sodo Kecamatan Paliyan Sebagai Bahan Pembelajaran .... Prosiding ..., $6(2)$ $2-5$. http://eproceedings.umpwr.ac.id/ind ex.php/sendika/article/view/1236

Ratuanik, M., \& Kundre, O. T. (2018). Pemanfaatan Etnomatematika Kerajinan Tangan Anyaman Masyarakat Maluku Tenggara Barat dalam Pembelajaran. Prosiding Seminar Nasional Etnomatnesia, 416-423.

S. Sirate, F. (2012). Implementasi Etnomatematika Dalam Pembelajaran Matematika Pada Jenjang Pendidikan Sekolah Dasar. Lentera Pendidikan: Jurnal Ilmu Tarbiyah Dan Keguruan, 15(1), 41-54. https://doi.org/10.24252/lp.2012v15 n1a4
Sayu, S. (2013). Eksplorasi etnomatematika dalam menganyam caping masyarakat dayak ribun. $1-11$.

Suciati, R., \& Kusuma, A. B. (2019). Eksplorasi Etnomatematika Pada Anyaman Bambu. Prosiding Sendika, 5(1), 252-259. http://eproceedings.umpwr.ac.id/ind ex.php/sendika/article/view/719

Wahyuni, A., \& Pertiwi, S. (2017). Etnomatematika dalam ragam hias melayu. Math Didactic: Jurnal Pendidikan Matematika, 3(2), 113-118. https://doi.org/10.33654/math.v3i2. 61

Wulandari, M. R., \& Nuhamara, Y. T. I. (2020). Eksplorasi Tenun Ikat Sumba Timur Ditinjau dari Etnomatematika. Satya Widya, 36(2), 105-115. 